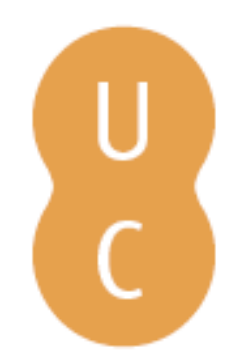

\title{
pombalina
}

\section{Elementos da convergência na educação: perspectivas para o ensino superior}

Autor(es): $\quad$ Campos, Fernanda Araujo Coutinho; Fidalgo, Fernando Selmar Rocha

Publicado por: Imprensa da Universidade de Coimbra

URL

persistente: URI:http://hdl.handle.net/10316.2/47387

DOI: $\quad$ DOI:https://doi.org/10.14195/978-989-26-1716-9_11

Accessed : $\quad$ 26-Apr-2023 12:00:26

A navegação consulta e descarregamento dos títulos inseridos nas Bibliotecas Digitais UC Digitalis, UC Pombalina e UC Impactum, pressupõem a aceitação plena e sem reservas dos Termos e Condições de Uso destas Bibliotecas Digitais, disponíveis em https://digitalis.uc.pt/pt-pt/termos.

Conforme exposto nos referidos Termos e Condições de Uso, o descarregamento de títulos de acesso restrito requer uma licença válida de autorização devendo o utilizador aceder ao(s) documento(s) a partir de um endereço de IP da instituição detentora da supramencionada licença.

Ao utilizador é apenas permitido o descarregamento para uso pessoal, pelo que o emprego do(s) título(s) descarregado(s) para outro fim, designadamente comercial, carece de autorização do respetivo autor ou editor da obra.

Na medida em que todas as obras da UC Digitalis se encontram protegidas pelo Código do Direito de Autor e Direitos Conexos e demais legislação aplicável, toda a cópia, parcial ou total, deste documento, nos casos em que é legalmente admitida, deverá conter ou fazer-se acompanhar por este aviso. 

FERNANDA ARAUJO COUTINHO CAMPOS

Doutora em Educação pela Universidade Federal de Minas Gerais (UFMG).

fernandaaccampos@gmail.com

FERNANDO SELMAR ROCHA FIDALGO

Professor Titular do Departamento de Administração Escolar da Faculdade

de Educação da Universidade Federal de Minas Gerais.

fernandos@fae.ufmg.br

\section{ELEMENTOS DA CONVERGênCIA NA EDUCAÇÃO : PERSPECTIVAS PARA O ENSINO SUPERIOR}

\section{Introdução}

Convergência ${ }^{1}$ significa tender para um ponto em comum. Pode ser, por exemplo, a tendência de integrar elementos da telecomunicação e da informática, ou dos meios de comunicação de massa e das tecnologias digitais, ou, ainda, no caso da educação, especialmente, do ensino superior a integração dos métodos tradicionais de aprendizagem com os da educação online. Em que, independente dos elementos, o essencial da convergência tratada neste trabalho é a tendência das relações sociais e educativas estabelecidas quando são utilizadas as tecnologias digitais da informação e da comunicação na educação, seja presencial ou a distância. A convergência se vislumbra como uma temática transdisciplinar e polissêmica.

Deste modo, a convergência, a qual nos referimos, diz respeito aos equipamentos tecnológicos e das relações culturais e sociais estabelecidas em rede. De tal modo, concordamos com Castells (2013) que acredita ser “(...) a convergência fundamentalmente cultural, e produz-se, em primeiro lugar nas mentes dos sujeitos comunicadores que integram vários modos e canais de comunicação e na sua interação" (Castells, 2013, p. 188).

\footnotetext{
1 Dicionário da Língua Portuguesa (2011, p. 420).
} 
Neste trabalho especificamente apresentamos de forma sintética, os elementos constitutivos da convergência na educação ${ }^{2}$. Em que buscamos refletir: o que é essencial na convergência? Qual o objetivo da convergência na educação? Como a convergência pode ser compreendida como uma alternativa para o ensino superior?

A elaboração da noção de convergência na educação iniciou-se a partir da constatação do uso cada vez mais constante da educação a distância conjugada ao ensino presencial. Ao longo do processo de doutoramento construímos e reconstruímos as nossas ideias e perspectivas do que se constituiria a convergência na educação. Inicialmente tínhamos como perspectiva de que a convergência se daria, de forma linear, pela integração da educação presencial e da educação a distância (EaD). Nesta perspectiva realizamos um estudo do histórico das modalidades - presencial e a distância - e um estudo documental das políticas para o ensino superior com recorte para a educação a distância tendo como mote a Portaria 4059/2004³, que definiu o semipresencial.

Ao decorrer da investigação, verificamos que a convergência na educação não é algo linear, antes pelo contrário, se consolida nas relações sociais criadas em rede e mediadas por Tecnologias Digitais da Informação e da Comunicação (TDIC) e, ampliam os paradigmas educacionais, os locais de ensinar e aprender, as relações entre os sujeitos - professores e estudantes. Compreendemos que a convergência se verifica como uma tendência do presente com o olhar para o futuro.

Compreendemos, portanto, que a convergência na educação propõe reflexões sobre os paradigmas educacionais tradicionais, os modos de ensinar e de aprender, o tempo e o espaço, a ampliação dos espaços de trocas de conhecimento, as políticas educacionais, as modalidades presenciais e a distância; assim como, nas formas de se relacionar e produzir novos conhecimentos

2 Estes elementos foram desenvolvidos de forma ampla na tese de doutoramento intitulada "Convergência na educação: políticas, tecnologias digitais e relações pedagógicas" (Campos, 2017).

3 Esta Portaria permitiu às instituições de ensino superior, à introdução de atividades didáticas, módulos ou unidades de ensino na modalidade semipresencial. Informamos aos nossos leitores que esta Portaria foi revogada em 2016, por meio da Portaria 1134/2016. 
que envolvem a colaboração, a partilha, a participação, a horizontalização, as comunidades de aprendizagem, a interação, a mediação, os ambientes virtuais de aprendizagem, a socialização, a autonomia e as redes; constituindo os elementos da convergência na educação. Sendo estes os elementos globais constitutivos da convergência na educação.

\section{Procedimentos Metodológicos}

Os procedimentos metodológicos utilizados na investigação, realizada em nível doutoral, denominada "Convergência na educação: políticas, tecnologias e relações pedagógicas", de perspectiva qualitativa,, foram divididos em eixos e sub eixos: 1) Eixo Analítico, dividido nos sub eixos "Políticas públicas para o ensino superior: recortes para a convergência", "Dimensões da convergência", "Elementos da convergência" e "Presença e distância"; 2) Eixo operacional desenhou os caminhos e definiu os instrumentos da investigação - dividido nos sub eixos "Metodologia Filosófica", "Análise documental" e "Estágio doutoral sanduíche".

A análise documental constituiu-se de 47 documentos entre legislações gerais sobre a educação, legislações específicas para educação a distância, legislações específicas sobre a Universidade Aberta do Brasil e de Portugal, referenciais de qualidade para a educação a distância e documentos complementares. Este estudo teve como marco temporal o ano de 1996 até 2014, sendo o inicial o da publicação da Lei de Diretrizes e Bases da Educação Nacional (LDBN/1996) e o ano final da publicação do "Texto Orientador para a Audiência Pública sobre a Educação a distância (Brasil, 2014) ' Os documentos portugueses foram incorporados no momento do estágio sanduíche, pois, inicialmente não estava prevista esta análise, portanto, o corte temporal corresponde ao mesmo realizado na análise documental brasileira.

O "Estágio Sanduíche" ${ }^{4}$ realizado na Universidade Aberta de Portugal (UAb) constituía-se como um dos eixos metodológicos da investigação. Para além do amadurecimento pessoal e profissional, foi fundamental para a ampliação

\footnotetext{
4 Programa de Doutorado Sanduíche (PDSE) - realizado com financiamento da CAPES entre agosto de 2014 e setembro de 2015 (Processo PDSE 99999.004239/2014-08).
} 
da hipótese inicial. Nesta instituição tivemos a oportunidade de conhecer as ofertas em nível superior realizadas de forma exclusivamente virtual; que utilizam uma plataforma de aprendizagem com estratégias de aprendizagem que viabilizam a constituição de comunidades em rede e de práticas colaborativas.

Neste trabalho, em especial, sublinhamos o sub eixo analítico "os elementos da convergência na educação" e sub eixo operacional "metodologia filosófica" (Folsched e Wudenburger, 1997) - quando nos debruçamos sobre artigos, teses, dissertações e obras acadêmicas, com o intuito de refletir filosoficamente sobre as publicações e de forma a nos tornamos capazes de construir um texto com as nossas próprias ideias e argumentos. Para o qual tínhamos como objetivo identificar os elementos da convergência na educação e suas perspectivas para o ensino superior.

A operacionalização dos sub eixos supracitados se deu a partir do levantamento bibliográfico realizados em bibliotecas institucionais, plataformas virtuais de revistas científicas, assim como de repositórios científicos, nomeadamente, o Scientific Eletronyc Library Online (Scielo), a Base de Teses de Coordenação de Aperfeiçoamento de Pessoal de Nível Superior (CAPES), o Google Acadêmico, a Biblioteca do conhecimento Online (B-on) e o Repositório Científico de Acesso Aberto de Portugal (RCAAP) e da análise e reflexão sobre os mesmos.

Foram localizados 62 publicações entre artigos, dissertações e teses, as quais as palavras chave para a pesquisa foram: blended learning, convergência na educação, educational convergence, semipresencial, bybrid educational e educação híbrida. Assim distribuídos:

QUADRO 1: Resultado da busca de artigos, dissertações e teses em repositórios científicos.

\begin{tabular}{|c|c|c|c|c|}
\hline Base de dados & Número de publicações & Teses & Dissertações & Artigos \\
\hline Oasis & 4 & 1 & 1 & 2 \\
\hline B-on & 31 & 1 & 2 & 28 \\
\hline Scielo & 3 & - & - & 3 \\
\hline RCAAP & 24 & 2 & 5 & 17 \\
\hline Total & 62 & 4 & 8 & 50 \\
\hline
\end{tabular}


A partir do material encontrado e seguindo os preceitos da metodologia filosófica, pudemos elaborar a compreensão da convergência na educação e seus principais elementos, conforme veremos nos tópicos a seguir:

\section{Convergência na Educação}

Historicamente constatamos que a educação presencial e a educação a distância constituíram paralelamente, em instituições específicas para cada uma delas e com fronteiras muito bem definidas. Desde sempre, portanto, foi estabelecida uma dicotomia e uma hierarquia entre elas, conforme Mill (2012) “(..) elas são concebidas com hierarquias - em que, geralmente, a EaD é tomada como uma subcategoria”. (Mill, 2012, p. 287).

As primeiras iniciativas de educação a distância ocorridas entre o século XIX e meados do século XX encontravam-se desvinculadas das instituições escolares e das universidades estando direcionadas para a alfabetização, para a profissionalização ou para a preparação de concursos do público adulto. Eram ofertadas sobremaneira via correspondência, rádio e televisão (Moore \& Kearsley, 2007; Peters, 2002). Em outras palavras, se constituía como uma modalidade educativa em que os sujeitos da aprendizagem - professores e estudantes - estão em locais e tempos distintos em que as tecnologias da informação são utilizadas como mediadores.

Nem mesmo a criação das universidades abertas a distância, a partir da década de 1960 - tal como a Open University (OU) no Reino Unido, a Universidad Nacional de Educación a Distancia (UNED) na Espanha ou a Universidade Aberta em Portugal (UAb) - realizou a integração da educação presencial e a EaD. Uma vez que a vocação destas instituições era exclusivamente o ensino a distância. Entretanto, trouxeram novidades para o EaD: abarcar o nível superior e desenvolver novas formas de combinação de trabalho e estudo, introduzir estudos regulares para adultos, manter o aprendizado aberto e permanente, ampliar cada vez mais a aplicação de tecnologias educacionais combinando áudio/vídeo e correspondência (ou seja, de multimídias) e viabilizar o apoio presencial (Peters, 2002). 
Entretanto, durante a década de 1990 e a primeira década do século XXI, o desenvolvimento das tecnologias digitais da informação e da comunicação consolidou ferramentas de interação que permitiu novas propostas de comunicação e de atividades nas instituições escolares. Um dessas propostas aliada a organização institucional foi denominada de blended learning.

De forma generalizada, o blended learning constitui-se por uma abordagem pedagógica que envolve tanto situações de aulas presenciais quanto situações de aulas online, numa combinação de várias abordagens pedagógicas, de métodos de aprendizagem e de várias tecnologias, que envolvem a cooperação, a autonomia e a interação social, em momentos síncronos e assíncronos.

Monteiro e Moreira (2013) consideram o blended learning

[...] como uma estratégia dinâmica que envolve diferentes recursos tecnológicos, diferentes abordagens pedagógicas e diferentes espaços. Ou seja, para além, da questão da integração de momentos presenciais e não presenciais, devemos ter em conta também a conjugação de diferentes abordagens de ensino a interação de diversos recursos tecnológicos e a adoção dos diferentes espaços de vida no processo de ensino aprendizagem. (Monteiro \& Moreira, 2013, p. 33-34).

Conforme Graham (2005), o blended learning desenvolve-se em 4 níveis: da atividade, da disciplina, do curso e da instituição. De modo geral, o blended learning torna-se realidade das instituições tradicionais do ensino presencial quando estas incorporam ou se constituem de todos os referidos níveis.

Ao incorporar todos estes níveis, finalmente, se verifica a integração da educação presencial e da educação a distância. Porém, para a ocorrência da convergência ainda são necessários a contemplação de outros elementos, sobremaneira as relações estabelecidas em rede.

Compreendendo este processo, a Portaria 4.059/2004 torna-se caduca. Desfazendo o que desde o início da investigação acreditávamos ser parte fundamental da integração da educação presencial e da educação a distância.

Essa Portaria permitia “(...) introduzir, na organização pedagógica e curricular de seus cursos superiores reconhecidos, a oferta de disciplinas integran- 
tes do currículo que utilizem modalidade semipresencial" (Brasil, 2004, art $\left.1 .^{\circ}\right)$ em que semipresencial se definia por

(...) como quaisquer atividades didáticas, módulos ou unidades de ensino-aprendizagem centrados na autoaprendizagem e com a mediação de recursos didáticos organizados em diferentes suportes de informação que utilizem tecnologias de comunicação remota (Brasil, 2004, art. 1. ${ }^{\circ}$ )

Desta maneira, deixamos de parte a análise desta Portaria. Suas definições eram restritas, limitadas à compreensão do semipresencial como atividades a distância, de modo complementar as disciplinas. Não incorporava à educação a distância às práticas globais das instituições ou dos cursos. Tampouco, revela as possíveis relações entre os sujeitos, dando continuidade à dimensão tecnicista da autoaprendizagem. Acreditamos que esta Portaria não apresenta procedimentos suficientes para consubstanciar a convergência na educação. Atentamos que um dos processos da convergência se faz no rompimento da dicotomia entre a educação presencial e a educação distância e, no repensar das relações educativas.

Os elementos da convergência na educação se constituem de princípios próprios dos tempos do informacionalismo, da sociedade em rede e global, em que o ciberespaço surge como um novo espaço, e das transformações sociais. Relaciona-se com as tecnologias digitais da informação e da comunicação, que estabelece novos tempos e espaço, incentiva a promoção da reorganização disciplinar, compreende as novas relações entre o homem e a máquina e os outros homens, mas não se delimita por estas tecnologias.

Após os nossos estudos, compreendemos que a convergência na educação se caracteriza pela flexibilidade curricular, pela aprendizagem aberta, pela flexibilização espaço temporal, pelos conteúdos abertos, pelas tecnologias digitais, pela participação, pela interação, pela colaboração, pela partilha, pelas comunidades online, pela multiplicidade, pela horizontalidade e pelos materiais didáticos.

A partir destas características, definimos que os elementos da convergência se constituem por: flexibilidade curricular, interação e colaboração, 
comunidades de aprendizagem, blended learning e mobile learning, recursos didáticos, convergência na sala de aula, convergência das TDIC no currículo. As principais ideias sobre os elementos da convergência na educação foram sintetizadas:

1. Flexibilidade curricular: refere-se a maleabilidade dos processos. De garantir a flexibilidade comunicativa a qualquer hora e a qualquer lugar. De possibilitar a convergência do ensino presencial e a distância, mas não só, de flexibilizar espaços de aprendizagem e, sobremaneira, de não manter uma matriz curricular rígida, de possibilitar trajetórias alternativas (Mill, 2014; Silva, 2000).

2. Interação e colaboração: refere-se às relações sociais estabelecidas online e também offline, que privilegiam a produção colaborativa, o compartilhamento de informações, por meio da intersubjetividade (Garrison, Anderson \& Archer, 2001).

3. Comunidades de aprendizagem: se constituem em situações formais, informais e não formais e se caracterizam por formas de sociabilidade e de colaboração. São meios para pensar, criar, comunicar, intervir, que possibilitam oportunidades de aprendizado por interesses em comum (Monteiro, Januário \& Moreira, 2014; Jenkins, 2009; Dias, 2014).

4. Blended learning e Mobile learning: referem-se a processos institucionalizados da convergência, que pretendem incentivar a flexibilidade e a mobilidade das situações de aprendizagem, a partir da introdução de elementos virtuais e móveis (plataformas virtuais de aprendizagem, atividades presenciais e online, laboratórios virtuais, campus online e equipamentos como smartphones e tablets) (Monteiro, Moreira 2013; Farrow, 2011; Traxler, 2011).

5. Recursos didáticos: novos materiais que contribuem para a educação virtual e também presencial. Entre os exemplos mais emblemáticos referimos os Recursos Educacionais Abertos (REA), que estão abertamente disponíveis para uso dos educadores e dos estudantes, que podem incluir cursos completos, partes de cursos, módulos, livros didáticos, artigos de pesquisa, vídeos e softwares (Mallman et a.l, 2013). 
6. Sala de aula: refere-se a situação de salas de aulas presenciais em que frequentemente se utilizam de recursos digitais seja para consultar informações sobre o conteúdo estudado, aceder redes sociais, verificar e-mail, realizar trabalhos etc. Ou seja, viabiliza a situação de estar em dois espaços simultaneamente, físicos e virtuais. (Santos, 2012).

7. TDIC no currículo: a integração das TDIC no currículo oportuniza o letramento digital e viabilizam este uso nas práticas sociais de forma consciente e crítica. Permitiria à incorporação de diferentes didáticas e abordagens pedagógicas, a adaptação de materiais didáticos, a linguagem multimídia e uma reflexão sobre o ensino tradicional (Andrade, 2011; Valente \& Almeida, 2011).

\section{Compreensões da convergência para o ensino superior}

A convergência na educação não se constitui como prospecção futurológica. É uma tendência presente nas relações sociais e que, aos poucos, vai sendo incorporada aos modos de fazer a educação. Reconhecemos que a convergência se realiza nas relações sociais e nos usos sociais das TDIC que, estabelecidas em rede, podem estender para espaços físicos, assim como o contrário.

A convergência na educação acontece numa série de dimensões que pode ser compreendida por um lado com a integração da educação presencial e a distância, com o uso mobile learning, com a integração dos materiais didáticos, com o uso de tecnologias (integradas ou não ao currículo), com os jogos online, com os modos estar presente fisicamente ou virtualmente, com o modo de entender que os processos educativos são expandidos e não limitados, com a composição de comunidades de aprendizagem.

Entendemos que a convergência na educação acontece processualmente. Na atualidade, conseguimos visualizar os seus elementos. Chega às instituições pelo modo de como os sujeitos se relacionam nas redes fora das instituições e acontece tendo em conta as relações orgânicas e fluidas estabelecidas em rede, em que as TDIC são um meio, e não, um 
fim. A convergência na educação se fundamenta em teorias socioconstruvistas e as comunidades de aprendizagem alicerçam as relações e a conectividade.

A convergência na educação se compõe como um processo que não prevê substituir ou desaparecer com sistemas tradicionais. Em seu sentido formal, a convergência se caracteriza por contemplar situações de aprendizagem físicas e virtuais, em que, as instituições de ensino incorporam às tecnologias digitais para fins educativos; em que se destacam situações de aprendizagem em blended learning em que se propõe a convergência de múltiplos materiais e de linguagens.

Por outro lado, entendemos que a convergência acontece de forma fluida, sem obrigatoriedades ou processos burocráticos, ela acontece como parte da vontade dos envolvidos, em que o letramento digital e a conexão à internet é requerida para serem possíveis a criação e o estabelecimento de interações e colaborações em rede. Por isso, a convergência na educação se evidencia também na informalidade.

Compreendemos que a convergência se constitui como um processo que incluem as alterações sociais, culturais e educacionais que são dinamizadas com o uso social das TDIC, sejam elas formais ou informais.

\section{Conclusões}

Neste estudo compreendemos que a noção de convergência é um processo em que se utiliza as TDIC na educação - seja na educação presencial ou na educação a distância (inclusive na integração delas) - que são mediadoras. Entretanto, não se faz só por isso, mas, sobretudo, por: interação, colaboração, participação, partilha, comunidades de aprendizagem, ambientes virtuais de aprendizagem, conectividade, mobilidade, aprendizagem em rede, materiais didáticos, flexibilidade, compartilhamento, redes sociais, inteligência coletiva, integração de modalidades, comunicação, horizontalidade e multiplicidade; próprias do contexto informacional.

A concretização da convergência se faz nos usos sociais, nas interações, nas participações e nas colaborações. Nessa medida, não podemos negligen- 
ciar o papel das TDIC, ao mesmo tempo, não podemos aclamá-las como concretizadoras do processo da convergência na educação.

Outro ponto a ser considerado, se revela na ruptura da hierarquia entre a educação presencial e a distância, com a convergência na educação, ponderamos que o processo educativo deve acontecer independente do meio, do espaço ou do tempo, a finalidade deve ser sempre a educação.

A convergência na educação significa aprender na coletividade, junto com, tendo as TDIC como mediadoras em situações formais ou informais; inovação pedagógica, produção de conhecimento teórico e pedagógico; vivência em espaços híbridos, num constante físico e virtual, viabilizado pela conexão à internet; estudos flexíveis, dinâmicos, autônomos; relações sociais em rede; participar e colaborar; integrar educação presencial e educação distância, múltiplos materiais, linguagens e tecnologias, em que a distinção entre educação presencial e a distância não faça sentido.

Assim, o que inicialmente pensávamos ser uma possibilidade, no final, entendemos ser uma tendência presente nas relações sociais e educativas, que se constitui como um processo em desenvolvimento.

\section{Referências bibliográficas}

ANDRADE, L. A (2011). Educação a distância e ensino presencial: convergência de tecnologias e práticas educacionais. 146p. (Mestrado) - Faculdade de educação, Universidade de Campinas, São Paulo.

CAMPOS, F. A. C (2017). Convergência na educação: processos, tecnologias digitais e relações pedagógicas. 261 p. Tese. (Doutorado em Educação) - Faculdade de Educação, Universidade Federal de Minas Gerais, Belo Horizonte.

CASTELls, M (2013). O poder da comunicação. Lisboa: Fundação Galouste Gulbenkian.

DIAS, P (2004). Comunidade de aprendizagem e formação online. Nov@ Formação, a. 3, n. 3, p. 14-17.

Dicionário da Língua Portuguesa (2011). Porto: Porto Editora.

GARrison, R., Amderson, T., Archer, W (2001). Critical Thinking, Cognitive Presence, and Computer Conferencing in Distance Education. American Journal of Distance Education, v. 15, n.1, p.7-23, 2001. Disponível em: <http://cde.athabascau.ca/coi_ 
site/documents/Garrison_Anderson_Archer_CogPres_Final.pdf>. Acesso em: 28 set. 2015.

GOMEs, L. F. (2013). EAD no Brasil: Perspectivas e desafios. Avaliação, Campinas. Vv. 18 , n. 1, 13-22.

GRAHAM, C. R. (2005). Blended learning systems: definition, current trend and future directions. In: BONK, C. J. et al (Org.) The handbook of blended learning: global perspectives, local designs. São Francisco: Pfeiffer Publishing.

JENKINS, H. (2009). Cultura da convergência. 2. ed. São Paulo: Aleph.

MALlmanN, E. M., et al. (2013). Potencial dos recursos educacionais abertos para integração das tecnologias e convergência entre as modalidades na UFSM. Revista Eletrônica de Educação, v. 7, 2013, n. 2, 263-284.

MILl (2012), D. A Universidade Aberta do Brasil. En Litto, F; Formiga, M. Educação a Distância: o estado da arte (v. 2). São Paulo: Pearson Education do Brasil, p. 280-291.

MILL, D (2014). Flexibilidade educacional na cibercultura: analisando espaços, tempos e currículo em produções científicas da área educacional. RIED. Revista Iberoamericana de Educación a Distancia, volumen 17, n. 2, 97-126.

MONTEIRO, A.; Moreira. J. A (2013). O blended learning e a integração de sujeitos, tecnologias, modelos e estratégias. In: Monteiro, A.; Moreira, J. A.; Almeida, A. C.; Lecatre, J. A (Coord.). Blended learning em contexto educativo: perspectivas teóricas e práticas da educação. 2. ed. Santo Tirso: White Books.

MOORE, M.; KEARSLEY, G. (2011). Educação a distância: uma visão integrada. São Paulo: Cengange Learning, 2011.

PETERS, O. (2002). A educação a distância em transição. São Leopoldo: Editora Unisinos.

SANTOS, D. M. B. (2012). A convergência tecnológica líquida no contexto da sala de aula: um recorte no ensino superior público baiano sob a ótica docente. Programa de Pós-Graduação Educação da Universidade Federal da Bahia, Salvador.

SILVA, B. (2000). O contributo das TIC e da Internet para a flexibilidade curricular: a convergência da educação presencial e à distância. In: Pacheco, J. C.; Viana, I. (Org.). Actas do IV Colóquio sobre questões curriculares (277-298). Braga: Universidade do Minho, 2000. p. 277-298.

VALENTE, J. A.; ALMEIDA, M. L (2011). Tecnologias e currículo: trajetórias convergentes ou divergentes? São Paulo: Paulus. 


\section{Legislação}

Portaria n. ${ }^{\circ} 4.059$ de 10 de dezembro de 2004. Regulamenta a oferta de carga horária a distância em disciplinas presenciais. Diário Oficial da União. Disponível em: $<$ http://portal.mec.gov.br/sesu/arquivos/pdf/nova/acs_portaria4059.pdf>. Acesso em: 09 out. 2012.

Conselho Nacional de Educação. Texto orientador para a audiência pública sobre Educação a Distância, 2014. Disponível em: <http://portal.mec.gov.br/index. php?option=com_docman\&task=doc_download\&gid=16558\&Itemid=>. Acesso em: 17 abr. 2015.

Lei n. ${ }^{\circ}$ 9.394/96, de 20 de dezembro de 1996. Estabelece as diretrizes e bases da educação nacional. Leis ordinárias. Brasília: Casa Civil da Presidência da República Federativa do Brasil/Subsecretaria para Assuntos Jurídicos, 1996. Diário Oficial da União. Disponível em: <http://www.planalto.gov.br/ccivil_03/Leis/ L9394.htm>. Acesso em: 14 jul. 2015. 
(Página deixada propositadamente em branco) 


\section{NOTAS B IOGRÁ F I CAS}

\section{Adriana Rocha Bruno}

É Pós doutora em Educação pelo Instituto de Educação da Universidade de Lisboa-PT, Doutora e Mestre em Educação: Currículo pela Pontifícia Universidade Católica de São Paulo e licenciada em Pedagogia. É professora Associada do Depto. de Educação, da Universidade Federal de Juiz de Fora (UFJF), professora dos Programas de Pós-Graduação em Educação e em Gestão e Avaliação da Educação Pública - ambos da UFJF. É coordenadora do Curso de Especialização Mídias na Educação (FACED/UFJF) e membro do NDE - Núcleo Docente estruturante do Curso de Pedagogia - UFJF. É líder do Grupo de Pesquisa Aprendizagem em Rede - GRUPAR, que conta com pesquisadores e estudiosos envolvidos em investigações sobre as Docências contemporâneas, a Aprendizagem do adulto em ambientes em rede e a formação docente em meio à Cultura Digital. É pesquisadora da FAPEMIG, da CAPES e membro de duas redes internacionais de pesquisa: REGIET (Red Internacional de Grupos de Investigación en Educación y Tecnología, UPM), COLEARN (Collaborative Open Learning, The Open University). Coordenou os tutores a distância do Curso de Pedagogia - FACED-UFJF-UAB (2009-2015). Foi Coordenadora de Inovação Acadêmica e Pedagógica no Ensino Superior (CIAPES) junto à PROGRAD-UFJF no período de 2011 a 2014. Foi professora da PUC-SP entre 2004 e 2008, no Departamento de Fundamentos da Educação, como docente de Didática para as licenciaturas e professoras nos Cursos: Tecnologias e Midias Digitais e Comunicação e Multimeios. Experiente na área de Educação, pesquisa, principalmente a partir dos seguintes temas: Formação de professores, Docência no Ensino Superior, Educação online e cibercultura, Didática, Aprendizagem de adultos, Neurociência e neuropsicologia, Linguagem emocional e Educação, mídias e tecnologias.

E-mail: adriana.bruno@educacao.ufjf.br

Orcid: https://orcid.org/0000-0002-5646-8919 


\section{Ana Carolina Guedes Mattos}

Doutoranda em Educação pela Universidade Federal de Juiz de Fora (PPGE/UFJF); possui mestrado em Educação pela UFJF; é especialista em Educação no Ensino Fundamental pelo Colégio de Aplicação João XXIII, da UFJF; formada em Comunicação Social na Universidade Estácio de Sá de Juiz de Fora (UNESA-JF); formada em Pedagogia, pela UFJF. É pesquisadora do Grupo de Pesquisa Aprendizagem em Rede (GRUPAR-UFJF) desde 2009, estudando educação online, formação de professores, mediação e utilização da hipermídia na educação, educação aberta e Recursos Educacionais Abertos (REA). Atualmente é professora da Rede Municipal de Educação de Juiz de Fora, atuando nos Anos Iniciais; é tutora da Especialização em Mídias na Educação da Universidade Aberta do Brasil, na UFJF (UAB-UFJF). Atuou no curso de Pedagogia (UAB-UFJF) durante três anos (2012-2015), trabalhou dois anos na Secretaria Estadual de Educação, nos Anos Iniciais (2016-2018) e como professora Substituta do Colégio de Aplicação João XXIII da UFJF, nos Anos Iniciais (2015-2017), foi professora dos Anos Iniciais na Rede Municipal de Educação de Juiz de Fora em 2014. Ministra cursos de Formação de Professores para o uso das Tecnologias Digitais da Informação e Comunicação aliadas à Educação. Atualmente pesquisa os seguintes temas: Educação Aberta, Massive Open Online Courses (MOOC), Recursos Educacionais Abertos (REA), Educação online e Cibercultura.

E-mail: carolguededmat@gmail.com

Orcid: https://orcid.org/0000-0002-8997-5896

\section{André Garcia Corrêa}

Licenciado em Música pela Universidade Federal de São Carlos. Mestre em Educação pela Linha de Pesquisa Formação de Professores e Outros Agentes Educacionais, Novas Tecnologias e Ambientes de Aprendizagem na Universidade Federal de São Carlos. Doutorando na mesma Universidade onde pesquisa a produção científica no Brasil em Educação e Tecnologias Digitais de Informação e Comunicação sob a perspectiva da sociologia da ciência. Na performance musical atua como Clarinetista. Primeiro Clarinete e clarinetista solo da Orquestra Experimental da Universidade Federal de São Carlos, entre 2006 e 2014, e membro do Quarteto de Clarinetas Sopra-4 entre 2009 e 2014. Atualmente é solista de grupos de música popular brasileira (samba e choro) na cidade de São Carlos, interior do Estado de São Paulo, Brasil. Trabalhou na área de Educação Musical como tutor virtual, foi supervisor de tutoria virtual e ministrou também disciplinas, como professor, no curso de Licenciatura em Educação Musical 
na Universidade Aberta do Brasil - Universidade Federal de São Carlos modalidade a distância. Atualmente é professor de Artes do Instituto Federal de Educação, Ciência e Tecnologia de São Paulo campus São Carlos.

E-mail: andregcorrea@gmail.com

Orcid: https://orcid.org/0000-0001-5044-1961

\section{Daísa Teixeira}

Professora da disciplina Tecnologias da Informação e da Comunicação como Apoio Educacional, no curso de Pedagogia, da Universidade Federal do Espírito Santo-UFES. Possui graduação em Letras/Português pela Universidade Federal do Espírito Santo (1976), mestrado em Educação pela Universidade Federal do Espírito Santo (2001), doutorado em Educação pela Universidade de São Paulo (2006) e pós-doutorado pela Universidade Aberta de Portugal (2017), com ênfase em Educação a Distância e e-Learning. Membro efetivo do Centro de Investigação Joaquim Veríssimo Serrão, Santarém-Portugal. Coordenadora do curso de Licenciatura em Pedagogia EAD/UFES, em parceira Capes/UAB/UFES, no período de 2015 a 2016. Lidera o Núcleo de Estudo e Pesquisa sobre Hipertexto e Tecnologia Educacional-NEPEHTE. Integra o Grupo de Estudo e Pesquisa sobre Humanização e Técnica - GEPHT. Tem interesse nos seguintes temas: Educação a Distância e e-Learning; Tecnologias Digitais e Educação; Formação de Professores em Ambientes Virtuais; Cultura Digital; Humanização e Técnica.

E-mail: daisat@uol.com.br

Orcid: https://orcid.org/0000-0001-9934-4791

\section{Daniel Mill}

Professor da Universidade Federal de São Carlos (UFSCar), onde trabalha como Docente e Gestor de Educação a Distância (EaD). Doutor em Educação pela UFMG, com pós-doutorado pela Universidade Aberta de Portugal. É membro do Programa de Pós-Graduação em Educação e do Programa de Pós-Graduação em Ciência, Tecnologia e Sociedade. É Líder do Grupo Horizonte (Grupo de Estudos e Pesquisas sobre Inovação em Educação, Tecnologias e Linguagens) e, como pesquisador, tem interesse particular pela interseção das temáticas: Trabalho Docente, Tecnologias, Linguagens, Cognição e Educação a Distância.

E-mail: mill.ufscar@gmail.com

Orcid: https://orcid.org/0000-0002-8336-3645 


\section{Diene Eire Mello}

Graduada em Pedagogia com Mestrado em Tecnologia pela Universidade Tecnológica Federal do Paraná (1997). Doutora em Educação pela UEM (2010). Pós-doutorada em Educação com foco em e-learning pela Universidade Aberta de Portugal (2015). É docente da Universidade Estadual de Londrina no Paraná na área de Didática, Formação de Professores e Tecnologias Educativas. Tem experiência na área de Educação, com ênfase em formação de professores, atuando principalmente nos seguintes temas de pesquisa: formação de professores, ensino, educação, tecnologias e aprendizagem e educação a distância.

E-mail: diene.eire.mello@gmail.com

Orcid: https://orcid.org/0000-0001-6048-8130

\section{Dulce Márcia Cruz}

Professora Associada da Universidade Federal de Santa Catarina (UFSC) no Departamento de Metodologia de Ensino, Universidade Aberta do Brasil e no Programa de Pós-Graduação em Educação do Centro de Ciências da Educação. Líder do Grupo de Pesquisa EDUMíDIA: Educação, Comunicação e Mídias no CNPq. Graduação em Comunicação Social - Rádio e TV - pela Fundação Armando Álvares Penteado, mestrado em Sociologia Política pela Universidade Federal de Santa Catarina, doutorado em Engenharia de Produção pela Universidade Federal de Santa Catarina. Foi professora do Mestrado em Ciências da Linguagem da Universidade do Sul de Santa Catarina e do Curso de Comunicação Social da Universidade Regional de Blumenau. Pesquisa na área de Educação e Mídias, na interface entre a Comunicação, a Educação e a Linguagem: Letramentos; Games e educação; Formação docente para as mídias digitais no ensino presencial e a distância; Linguagens e narrativas na cultura digital; Processos, práticas de produção e análise dos gêneros digitais. Tem projetos financiados pela CAPES/CNPq/RNP para produção do Game Comenius: o jogo da Didática. Bolsista Produtividade do CNPq.

E-mail: dulce.marcia@gmail.com

Orcid: https://orcid.org/0000-0001-7055-0137

\section{Edméa Santos}

Pedagoga pela UCSAL, mestre e doutorada em Educação pela UFBA. Pós-doutora em e-learning e EAD pela UAB-PT. Professora da Universidade Rural do Rio de Janeiro. Atua no PROPED - Programa de Pós-Graduação em Educação. Linha de Pesquisa: 
\&quot;Cotidianos, redes educativas e processos culturais\&quot;. Líder do GPDOC Grupo de Pesquisa Docência e Cibercultura. Membro do Laboratório de Imagem da UERJ. Coordenadora do GT 16 \&quot;Educação e Comunicação\&quot; da ANPED, membro (atualmente vice-presidente na gestão de 2018-2020) da diretoria do Conselho Científico Deliberativo e da ABCIBER - Associação de Pesquisadores em Cibercultura. Chefe da linha de pesquisa \&quot;Cotidianos, redes educativas e processos culturais\&quot; do PROPED/UERJ. Atua na formação inicial e continuada de professores e pesquisadores. Áreas de atuação: educação e cibercultura, formação de professores e pesquisadores, informática na educação, educação online, EAD, currículo, didática, pesquisa e práticas pedagógicas.

E-mail: edmeabaiana@gmail.com

Orcid: https://orcid.org/0000-0003-4978-9818

\section{Maria de Fátima Goulão}

É licenciada e mestre em Psicologia Educacional. É doutorada no ramo das Ciências da Educação, especialidade Formação de Adultos. Docente da Universidade Aberta desde 1995. Foi membro e diretora do Departamento de Ciências Sociais e Políticas. Foi vice-presidente do Conselho Científico. É atualmente docente do Departamento de Educação e Ensino a Distância. É membro do Senado da Universidade Aberta. É membro colaborador do Laboratório de Ensino a Distância e ELearning e da Unidade de Investigação e Desenvolvimento em Educação e Formação, Grupo de Psicologia Educacional, do Instituto de Educação de Lisboa. Tem participado em vários congressos nacionais e internacionais onde procura dissemina os resultados obtidos na sua investigação. Esta desenvolve-se no âmbito do ensino a distância, estilos de aprendizagem, ambientes virtuais de aprendizagem, papéis de professor e de estudante nestes ambientes de ensino. A sua investigação continua ainda desenvolver-se no âmbito dos fatores potenciadores da aprendizagem em ambientes online, como seja a autorregulação da aprendizagem, o sentimento de autoeficácia e o papel do suporte dado aos estudantes, em particular, o suporte pedagógico.

E-mail: fatimapgoulao@gmail.com

Orcid: https://orcid.org/0000-0002-2285-6753

\section{Fernanda Araujo Coutinho Campos}

Doutora em Educação pela Universidade Federal de Minas Gerais (UFMG), mestre em educação pela UFMG (2011), pós-graduada em educação a distância pelo SENAC 
Minas (2009), graduada em História pela Pontifícia Universidade Católica de Minas Gerais (2007). Atuando principalmente nos seguintes temas: tecnologias digitais, tecnologias e educação, convergência na educação, educação a distância, formação de professores.

E-mail: fernandaaccampos@gmail.com

Orcid: https://orcid.org/0000-0002-0841-5871

\section{Fernando Selmar Rocha Fidalgo}

É Professor Titular do Departamento de Administração Escolar (DAE/FaE) da Universidade Federal de Minas Gerais (UFMG), Doutor em Educação pela Pontifícia Universidade Católica de São Paulo (PUC/SP), Mestre em Educação pela UFMG e Pedagogo pela Universidade Federal do Rio Grande (FURG). Atualmente coordena o Observatório Nacional do Sistema Prisional (ONASP), o Programa de Capacitação dos Servidores do Sistema Prisional (CASSP) e o Núcleo de Pesquisas em Educação a Distância (CAED-UFMG). É membro do Colegiado do Programa de Pós-graduação em Educação da UFMG - orientando mestrados e doutorados, e do Núcleo de Estudos sobre Trabalho e Educação. Criador e Co-editor da Revista Trabalho \& Educação. Foi Diretor de Educação a Distância da UFMG (2010-2014). Foi pesquisador visitante no Institut de Recherches Economiques et Sociales (1996-1998). Realizou residência Pós-doutoral na Université Paris X (2003-2004) e, também, na Universidade do Porto (2009-2010). Bolsista de Produtividade do CNPq-Brasil.

E-mail: rochafidalgo@yahoo.com.br

Orcid: https://orcid.org/0000-0003-0799-4581

\section{José António Moreira}

Doutor e Mestre em Ciências da Educação pela Universidade de Coimbra. Realizou um Pós-Doutoramento em Tecnologias Educacionais e da Comunicação também pela Universidade de Coimbra. Possui Curso de Mestrado em Multimédia pela Faculdade de Engenharia da Universidade do Porto e Licenciatura em História da Arte pela Faculdade de Letras da Universidade de Coimbra. É Professor Auxiliar no Departamento de Educação e Ensino a Distância (DEED) da Universidade Aberta (UAb). Atualmente é Diretor da Delegação Regional do Porto da Universidade Aberta e Coordenador da Unidade de Desenvolvimento dos Centros Locais de Aprendizagem (UMCLA) da mesma universidade. É Coordenador Científico da Unidade Móvel de Investigação 
em Estudos do Local (ELO) e investigador no Centro de Estudos Interdisciplinares do Século XX (CEIS20) da Universidade de Coimbra e no Laboratório de Educação a Distância e eLearning (LE@d) da UAb. É ainda Coordenador do Núcleo de Estudos de Pedagogia no Ensino Superior (NEPES) sedeado no CEIS20. Tem publicado artigos científicos em revistas especializadas e livros nas áreas da Formação de Professores e das Tecnologias Digitais. E tem participado em eventos no estrangeiro e em Portugal como orador convidado e realizado investigação, sobretudo, na área da Educação Online.

E-mail: jmoreira@uab.pt

Orcid: https://orcid.org/0000-0003-0147-0592

\section{Lauro Roberto Lostada}

Mestre (2013) e Doutorando em Educação, na linha de Educação e Comunicação, pelo Programa de Pós-Graduação em Educação da Universidade Federal de Santa Catarina - UFSC. Possui graduação em Filosofia pela Universidade Federal de Santa Catarina (2004), Especialização em Práticas Pedagógicas Interdisciplinares pelas Faculdades Integradas FACVEST (2006) e Especialização em Mídias na Educação pela Universidade Federal do Rio Grande (2009). Atua, desde 2006, como Assistente Técnico Pedagógico na Escola de Educação Básica Irmã Maria Teresa, de Palhoça, em Santa Catarina. É integrante do Grupo de Pesquisa Edumídia (dgp.cnpq.br/dgp/espelhogrupo/7358330050350194). Tem experiência na área de Educação, atuando principalmente nos seguintes temas: tecnologias educacionais, educação a distância e formação de professores.

E-mail: lostada25@yahoo.com.br

Orcid: https://orcid.org/0000-0001-7891-7714

\section{Luciane Penteado Chaquime}

Licenciada e Bacharel em Ciências Sociais pela Universidade Estadual Paulista (UNESP) "Júlio de Mesquita Filho". Licenciada em Pedagogia pela Universidade Nove de Julho (UNINOVE). Mestra em Educação pela Universidade Federal de São Carlos (UFSCar), na linha de pesquisa "Formação de professores e outros agentes educacionais, novas tecnologias e ambientes de aprendizagem". É docente do ensino básico, técnico e tecnológico, área de Educação/Pedagogia, no Instituto Federal de Educação, Ciência e Tecnologia de São Paulo (IFSP), no câmpus de Matão. É integrante do Grupo Hori- 
zonte (Grupo de Estudos e Pesquisas sobre Inovação em Educação, Tecnologias e Linguagens). Atualmente faz doutorado no Programa de Pós-Graduação em Educação da UFSCar, na linha de pesquisa "Estado, Política e Formação Humana". Como pesquisadora, interessa-se pelos temas Educação a Distância, Trabalho docente e formação de professores, Educação e Tecnologias.

E-mail: luciane.penteado@gmail.com

Orcid: https://orcid.org/0000-0002-1837-5973

\section{Patricia Lupion Torres}

Possui graduação em Pedagogia pela Pontifícia Universidade Católica do Paraná (1981), mestrado em Educação pela Pontifícia Universidade Católica do Paraná (1994) e doutorado em Engenharia de Produção pela Universidade Federal de Santa Catarina (2002). Atualmente é Coordenadora do Programa de Pós-Graduação Stricto Sensu em Educação da PUCPR, professora titular da Pontifícia Universidade Católica do Paraná e Professora permanente do mestrado e doutorado em Educação da PUCPR. Diretora de EAD da Pró-reitoria de Extensão e Comunitária no período de 2005 a 2009. Professora da UFSC nos programas de Mestrado em Mídia e Conhecimento no período de 1999 a 2002. Gestora de projetos de utilização de ambientes virtuais de aprendizagem para oferta de disciplinas a distância em cursos superiores. Diretora da área de Educação da PUCPR no período de 1995 a 1999 e de 2003 a 2005. Membro do conselho diretor da PUCWEB no período de 2003 a 2005.Coordenadora do curso de Pedagogia no período de 2010 a 2014. Possui livros e capítulos de livros publicados na República Dominicana, no Peru, na Inglaterra, nos Estados Unidos, na Colômbia, no México, em Portugal, e no Brasil. Tem experiência na área de Educação, atuando principalmente nos seguintes temas: tecnologias educacionais, educação a distância, formação profissional, formação de professores, educação superior.

E-mail: ptorres@terra.com.br

Orcid: https://orcid.org/0000-0003-2122-1526

\section{Sara Dias Trindade}

Doutora em História - Didática da História. Professora Auxiliar Convidada no Departamento de História, Estudos Europeus, Arqueologia e Artes da Faculdade de Letras da Universidade de Coimbra. Investigadora no Grupo Humanidades Digitais e no Núcleo de Estudos em Pedagogia no Ensino Superior do Centro de Estudos Interdisciplinares 
do Século XX (CEIS20-UC) da Universidade de Coimbra, integrando, atualmente, a equipa de coordenação do referido Centro. É também investigadora na Unidade Móvel de Investigação em Estudos do Local da Universidade Aberta e em vários grupos de pesquisa de diferentes universidades brasileiras. Tem participado em diferentes projetos internacionais relacionados com as Tecnologias Educativas e com a Formação de Professores. As suas áreas de interesse e investigação são as da Didática, da Formação de Professores, das Tecnologias Educativas e do Cinema na Educação, tendo participado em diferentes publicações nacionais e internacionais e sido oradora convidada, tanto em Portugal como no estrangeiro, nessas mesmas áreas.

E-mail: sara.trindade@uc.pt

Orcid: https://orcid.org/0000-0002-5927-3957

\section{Susana Henriques}

É licenciada, mestre e doutorada em Sociologia pelo ISCTE - Instituto Universitário de Lisboa, Professora Auxiliar do Departamento de Educação e Ensino a Distância da Universidade Aberta e investigadora do Centro de Investigação e Estudos de Sociologia do Instituto Universitário de Lisboa. É Vice-Coordenadora Executiva da Unidade de Missão para os Centros Locais de Aprendizagem (UMCLA) da mesma universidade e Coordenadora da Linha 2 da ELO - Literacia e Inclusão Digital. Áreas de interesse na investigação: Sociologia da educação e da comunicação - elearning, literacia mediática, liderança educacional; Sociologia dos consumos e das drogas e educação para a saúde; Metodologias de investigação.

E-mail: susana.a.henriques@gmail.com

Orcid: https://orcid.org/0000-0002-7506-1401

\section{Terezinha Fernandes}

É professora adjunta da Universidade Federal de Mato Grosso. Doutora em Educação pela Universidade Federal de Santa Catarina (2016) com Doutoramento Sanduíche pela Universidade Aberta de Portugal (2015). Mestre em Educação pela Universidade Federal de Mato Grosso (2006). Especialista em Formação de Orientadores para EaD pela Universidade Federal de Mato Grosso (2002). Especialista em Psicopedagogia pelo Instituto Cuiabano de Educação (2000). Licenciada em Pedagogia pelas Faculdades Integradas de Diamantino (1997). Bolsista Prodoutoral Docente Capes (2012/2013 e 2016) e Bolsista Doutorado SWE CNPq - Ciências sem Fronteira (2014/2015). Mem- 
bro dos Grupos de Pesquisa Edumída/UFSC; Lêtece/UFMT e Gpdoc/UERJ. Atua na docência em cursos de graduação em Educação Presencial e a Distância (Online) nas áreas de Linguagens: Alfabetização, Letramentos, Literatura Infanto-juvenil e Fundamentos da EaD e no Programa de Pós-graduação em Educação na docência e na em pesquisa em Educação e Comunicação com os temas Letramentos Digitais, Educação Online, Tecnologias Educacionais e Cibercultura. Dentre outras atividades atualmente coordena o Núcleo de Educação Aberta e a Distância (NEAD), do Instituto de Educação, da Universidade Federal de Mato Grosso.

E-mail: terezinha.ufmt@gmail.com

Orcid: https://orcid.org/0000-0002-1040-424X

\section{Vivian Martins}

Doutoranda do Programa de Pós-graduação em Educação da Universidade do Estado do Rio de Janeiro (UERJ), possui mestrado em Educação pela UERJ, especialização em Planejamento, Implementação e Gestão da Educação a Distância pela Universidade Federal Fluminense (UFF) -2015, MBA em Gestão de Recursos Humanos pela UFF - 2011, Licenciatura e Bacharelado em Pedagogia pela UERJ - 2009. Professora de Educação a Distância e Tecnologias Educacionais do Instituto Federal de Educação, Ciência e Tecnologia do Rio de Janeiro (IFRJ). Membro do GPDOC - Grupo de Pesquisa Docência e Cibercultura (UERJ), do grupo Literacia visual: pesquisa, ensino e formação docente em Artes (IFRJ) e do SECRIA - Setores criativos: ensino, pesquisa e práticas pedagógicas (IFRJ). Possui experiência na área de Educação, com ênfase em Educação Online.

E-mail: vivian.martinst@gmail.com

Orcid: http://orcid.org/0000-0001-7239-1619 


\section{Organizadoras da publicação:}

\section{Daniela Melaré Vieira Barros}

Pedagoga, Especialista em Instrucional Designer, Especialista em Administração em Educação a Distância. Mestre em Engenharia dos Media para a Educação Euromime-Erasmus Mundus-Portugal, Espanha e França e Mestre em Educação pela UNESP-BRASIL. Doutoramento em Educação pela UNESP-BRASIL, Pós-Doutoramento pela UNICAMP e o segundo Doutoramento realizado e premiado pela UNED de Madrid. É Colaboradora da Open University, no projeto COLEARN e editora Colaboradora da Revista Estilos de Aprendizaje. Atualmente é docente Auxiliar da Universidade Aberta em Portugal. Áreas de interesse: aprendizagem no virtual e estilos de aprendizagem, educação a distância, e-learning, formação de professores e uso de tecnologias.

Email: Daniela.Barros@uab.pt

Orcid: https://orcid.org/0000-0002-1412-2231

\section{Ana Isabel Ribeiro}

Ana Isabel Ribeiro é investigadora integrada do Centro de Estudos interdisciplinares do século XX da UC (CEIS20), no grupo de Humanidades Digitais e no Núcleo de Estudos em Pedagogia no Ensino Superior e professora auxiliar do Departamento de História, Estudos Europeus, Arqueologia e Artes da Faculdade de Letras da Universidade de Coimbra (FLUC) onde tem lecionado nas áreas de história moderna de Portugal, metodologia de investigação histórica, didática da história e humanidades digitais. Coordena, na FLUC, o mestrado em ensino de História no $3 .^{\circ}$ ciclo do ensino básico e ensino secundário.

A sua principal linha de investigação tem-se centrado no estudo das relações sociais, familiares e patrimónios das nobrezas locais, nos séculos XVIII e XIX. Desenvolve, também, investigação no âmbito das humanidades digitais, nomeadamente na implementação e utilização bases de dados relacionais aplicadas à investigação histórica e na visualização e análise de redes sociais em História em na utilização e produção de conteúdos digitais para ambientes educativos.

E-mail: aribeiro@fl.uc.pt

Orcid: http://orcid.org/0000-0002-7515-2696 